\title{
Understanding the Neighborhood Concentration of Affluent Black Households in the 1990s
}

\author{
Ron Malega \\ Department of Geography, Geology and Planning, Missouri State University, Springfield, MO 65897, USA; \\ rmalega@missouristate.edu
}

Received: 15 November 2018; Accepted: 27 December 2018; Published: 4 January 2019

\begin{abstract}
This study examines the intersection of race, class, and place by exploring the neighborhood concentration of affluent black households in the United States during the 1990s using Census 2000 data. It adds to the literature seeking a more nuanced understanding of the black community. The author assesses the theories of spatial assimilation and place stratification in understanding the processes associated with the neighborhood-level concentration of affluent black households. Regression analyses reveal that, in general, such concentrations are positively associated with black neighborhood socioeconomic status and negatively associated with white status. Furthermore, neighborhood quality and demographic factors are important for understanding the geography of affluent black households. Additionally, the metropolitan characteristics of residential segregation, racial composition, and regional location affect the neighborhood concentration of affluent black households. Findings suggest place stratification theory provides greater explanatory power than spatial assimilation theory for understanding the neighborhood concentration of affluent black households.
\end{abstract}

Keywords: black household affluence; spatial assimilation; place stratification; residential segregation; neighborhood; negative binomial regression

\section{Introduction}

Residential location matters for an assortment of social, political, and economic reasons, including how such a location affects one's life chances. Not surprisingly, its causes and consequences continue to attract the attention of countless academic and policy debates. Such debates often center on measuring and explaining levels and changes in racial/ethnic segregation at the metropolitan level, investigating ecological mechanisms of neighborhood sorting, and ascertaining the continuing significance of race versus the increasing importance of class in determining residential outcomes. Aside from scholarly concerns, these debates matter to the extent that policies should be developed to address such residential outcomes, and if so, what form those remedies should take.

Residential outcomes of African Americans have been at the center of this debate for decades. While historically, African Americans have lived under conditions of hypersegregation [1], encouraging analysis based on the 2000 Decennial Census indicates that black residential segregation continued to decline nationally. (Please note, I use the term African American and black interchangeably throughout this paper; additionally, I do not distinguish between Hispanic and non-Hispanic blacks unless indicated.) Despite this positive trend, however, high levels of segregation still existed between blacks and whites [2-4]. Research focusing on higher status blacks found that they also experience high levels of residential segregation from whites, though somewhat less than lower-income blacks [5-10]. Complementary literature draws attention to how issues of race, class, and place negatively affect life chances [11-13]. A major emphasis of such investigations focuses upon poor, inner-city African Americans and the places where they reside-blighted neighborhoods experiencing concentrated 
poverty. In all, scholarship investigating the relationship between class, race, and place has been fragmented due to a fundamental conflation and a gap in the literature.

The literature has inadequately resolved the relative and continuing roles of race and class with respect to place. Some research suggests that, in particular, conflicting neighborhood racial preferences and increasingly economic class, rather than race per se, predict where blacks (and other groups) will residentially locate [14-18]. Other researchers maintain that race continues to be a significant barrier for African Americans and their residential placement, regardless of their class position or racial preferences $[8,10,19-21]$. While more recent studies on race and place have investigated middle-class blacks and the places in which they live [22-26], to date, there has been little serious exploration of affluent black households and their spatial outcomes [9].

The purpose of this paper is to investigate the neighborhood concentration of affluent black households and examine the ecological forces that affect such spatial outcomes at the neighborhood level. I use the term neighborhood concentration to refer to the number (or count) of affluent black households per neighborhood and not a neighborhood aggregation wherein lower-level geographies are combined to create higher-level geographies (e.g., block groups into census tracts). What distinguishes this research project from prior studies is that, substantively, it studies the spatial outcomes of an understudied segment of the African American community (i.e., affluent black households) and, methodologically, it assesses the theories used to understand these outcomes using a method (i.e., count regression) not commonly employed within this research tradition. I conceive the neighborhood concentration of affluent black households as represented by the absolute number of such households in a neighborhood, taking into consideration the potential number for such households in any given neighborhood. I define affluent households as those households making two or more times than the median household income for the metropolitan area in which a household resides. To better understand the processes associated with the neighborhood concentration of affluent black households, I aim to evaluate the utility of two commonly employed and competing theories of residential attainment: Spatial assimilation and place stratification. Gaining a better understanding of the neighborhood concentration of affluent black households at the neighborhood level will allow scholars to more fully comprehend and theorize the varied ways that race, class, and place intersect to affect residential outcomes of all African Americans.

\section{Literature Review}

Two existing theoretical perspectives of residential attainment guide this research project: Spatial assimilation and place stratification. Massey's $[27,28]$ model of spatial assimilation suggests that as immigrants' level acculturation and socioeconomic standing (SES) increase, they convert such achievements into an improved spatial position resulting in greater residential integration within mainstream (white) society. As the social distance between an immigrant group and mainstream society lessens, immigrants move from central city ethnic neighborhoods to better-quality suburban neighborhoods predominated by white residents [29].

Spatial assimilation theory would suggest that affluent black households are more capable of converting their socioeconomic gains into "better" (read "whiter") neighborhoods than are poorer black households. In other words, affluent black households should be less segregated from whites, and their white economic peers, than should their less affluent black counterparts. Some scholarship suggests that the predictive power of race may be decreasing, with class differences becoming increasingly important for understanding black residential segregation patterns $[7,8,19,30,31]$. Work by Iceland and Wilkes (2006), for example, finds evidence that spatial assimilation theory applied more during the 1990s than in previous decades. Their multivariate models suggest that higher-SES blacks saw a greater reduction in residential segregation from whites than lower-SES blacks. Research by Freeman [32] used panel study of income dynamics data to gauge the effects of various measures of black SES on neighborhood outcomes between 1970 and 2000. He found black SES had significant effects in determining individual blacks' neighborhood outcomes in terms of housing value, percentage of 
whites, and poverty rate. Freeman found support for spatial assimilation theory in that higher black SES was associated with more integration with whites and improved residential attainment for all decades of analysis. However, he found that the ability to translate such gains did not improve over the study period [32].

While spatial assimilation theory was developed with the goal of explaining the incorporation of early 20th Century U.S. immigrants in mainstream society, many recent U.S. immigrants now come to the U.S. with greater social and economic resources (i.e., English fluency, education, etc.) compared to the past. Furthermore, many immigrants locate directly into suburban neighborhoods, bypassing residence in the central city altogether $[19,28,33,34]$. Another criticism of the spatial assimilation model is that it does not accurately depict the residential experience of African Americans, black immigrants, or black Hispanics, many of whom experience high rates of residential segregation regardless of their level of acculturation or SES attainment [35-38].

Black-white wealth differences might account for this key criticism of spatial assimilation-its inapplicability for blacks. Oliver and Shapiro [39] demonstrated the disparity in wealth accumulation between blacks and whites is important towards our understanding of black-white racial inequality, including in housing outcomes. Their work suggests blacks' lower accumulation of wealth, rather than exclusively black-white income differences, may be a factor limiting blacks' ability to buy into the most affluent neighborhoods. In other words, those higher-income black households may be too wealth-poor to purchase homes in those higher-income white neighborhoods. (The disparity in wealth accumulation, however, is due to past and present racial discrimination and structured inequality, resulting in the cumulative disadvantage of wealth creation for blacks and cumulative advantage for whites, thereby reinforcing blacks' position at the bottom of the economic hierarchy [39].) Their lower-income white neighbors, however, may be unable to afford the premium to live in comparatively "whiter" (often read higher-status) neighborhoods. In other words, such white households may be too income-poor to "get out" of such neighborhoods in order to limit their residential exposure to black households. Thusly, affluent black households might be residentially integrating with lower-status white households rather than their white economic peers. Such an interpretation is in keeping with spatial assimilation theory if one argues higher-income blacks' gain status by moving into comparatively lower-income whiter neighborhoods or if you measure status with a significant wealth component.

Place stratification is an alternative theory of residential attainment that recognizes the inability of blacks to obtain the expected residential return on gains to their human capital [40]. It recognizes the role of racial/ethnic prejudice and preference, discrimination, and institutional/structural racism in constraining minority residential mobility, thereby shaping a residential landscape characterized by segregation $[8,41]$. Place stratification theory argues that places have a hierarchical ordering wherein higher ordered places provide a greater quality of life and more favorable life chances than lower ordered places. Such ranking takes place both within and between suburban areas and central cities. More advantaged social groups use the hierarchy of places to help to preserve their social distance between them and less advantaged groups. Furthermore, the model suggests racial and ethnic minorities are sorted along the hierarchy of place depending on each group's standing in society. Therefore, individual members of some groups do not have the same opportunity (if at all) to convert their gains in socioeconomic standing to living in more desirable, higher-ranked places [42].

A number of sources provide support for the applicability of place stratification theory to African Americans. Housing discrimination is one barrier argued to restrict the housing choices and outcomes for blacks at all SES levels. The literature on housing discrimination shows that blacks continue to face discrimination in the housing market compared to whites, including adverse treatment, such as the denial of information and home seeking assistance, less favorable financial terms, and geographic steering. More specifically, black homebuyers and are being steered away from predominately white and affluent neighborhoods and into minority and mixed neighborhoods [12,43,44]. 
In addition to housing discrimination, it has been argued place stratification maintains the neighborhood racial hierarchy via racial group preferences, especially out-group avoidance resulting from negative racial stereotyping; such preferences work to sustain segregated communities $[41,45]$. Theories of racial preference suggest that while all racial/ethnic groups tend to prefer living in neighborhoods where their group is highly represented or the majority, whites consistently display the least willingness to live in racially and ethnically integrated neighborhoods [46]. Blacks, in particular, are the "least desirable" neighbors to whites, even when controlling for black SES [18,47-50].

Racial preferences, of all groups, function to maintain the hierarchy of neighborhoods predicted by place stratification theory because such preferences affect the desirability, and possibly the stability, of integrated neighborhoods. Such preferences provide insight into the willingness of each racial group to maintain residence or move into a neighborhood with a particular racial mix. Survey results consistently show whites prefer neighborhoods where they form a significant majority of the residents and that they find blacks the least desirable neighbors. For whites, as the number of blacks increase in a neighborhood, the desirability of that neighborhood declines [41,46-48,51]. Furthermore, research indicates whites are willing to pay a premium in house prices to live in "whiter" neighborhoods [3,52-54]. By contrast, survey results suggest blacks prefer greater levels of integration than whites and are more comfortable being a numerical minority in a neighborhood, especially when those neighbors are white $[41,47,51,55]$.

Place stratification theory has been criticized for failing to explicitly incorporate racial/ethnic neighborhood preferences into residential attainment models [5,29]. Additionally, while place stratification theory recognizes that quality of life, and life chances, are unequally sorted along the hierarchy of places, its conceptualization of quality of life is often weakly operationalized, thereby limiting its explanatory utility and understanding of the causes and consequences of such a hierarchy. (This is often determined using a neighborhood's percentage of white residents or an individual's residential location in the central city versus suburb as an indicator of both quality and access to place.) The theory may also be charged with privileging the white middle-class suburban "norm" as the uncritical standard from which to measure the hierarchy of place and access to place.

To summarize, I seek to understand which commonly presented theory of residential attainment—spatial assimilation or place stratification — better explains the concentration of affluent African American households at the neighborhood level. In short, if spatial assimilation theory provides a better description of the processes associated with the concentration of affluent black households, we would expect to find greater numbers of affluent black households in neighborhoods having relatively greater shares of whites, greater black and white group-level SES, and in metropolitan areas having less black-white residential segregation. If place stratification theory provides a better description, we would expect to find greater numbers of affluent black households in comparatively blacker (non-white) neighborhoods, among greater black and lower white SES, and in metropolitan areas having higher levels of segregation.

\section{Data and Methodology}

\subsection{Data}

The Neighborhood Change Data Base [56] provides Census 2000 data for this study. "Long form" Census 2000 data are used in this analysis because they provide a more accurate measure of the dependent variable compared to the more recent American community survey (ACS) data because the margins of error in the ACS, compared to the old decennial "long form," are too large to provide reliable estimates of count variables. Census tracts are the unit of analysis and often serve as a proxy for neighborhoods in the neighborhood effects, residential segregation, and residential attainment literature. I limited the sample to tracts located in metropolitan areas where the percentage of residents that self-identified as "non-Hispanic black alone" was greater than or equal to $3 \%$ of the total population or those area's having at least 20,000 black residents. (This method follows that used previously by 
Farley and Frey [2]. The sample does not include metropolitan areas located in Puerto Rico or any of the other U.S. possessions.) In order to provide reliable estimates of census tract characteristics, I further limited the sample to include those tracts meeting the following criteria: (1) A total population of at least 500 persons; (2) a group-quarters population consisting of not more than 50 percent of the total population; (3) a minimum of 30 black and white householders; (4) a median specified owner-occupied housing value greater than 0 ; and (5) a reported black and white per capita income greater than 0 . This resulted in a final sample of 26,686 census tracts throughout 229 metropolitan areas.

The dependent variable is the number of affluent black households in a neighborhood. Following census convention, I categorized households by race using the census designated self-reported race of the householder. Unlike poverty, where federal government guidelines are commonly used to identify poor persons or households, there is no agreed upon way of identifying affluent persons or households.

Previous research has attempted to define affluence with varying methods and results. Some researchers have suggested using the poverty level income for a four-person-household to identify affluent households. For example, they suggest that household (or family) income greater than four times the poverty thresholds indicates affluence $[57,58]$. A problem with this method is that the threshold is often very low. Other researchers have identified affluent households (families) as those having a household (family) income at least 1.5 to 2 times greater than the yearly national median household/family income $[59,60]$. The benefit of this method, compared to the previous, is that it estimates affluence more conservatively; such estimates of affluence are considered more consistent with the public's perception of affluence [59]. One problem with this second method is that because income levels and the cost of living can vary among metro areas, especially at the extremes, it risks overestimating the number of households in high cost areas and underestimating the number in lower cost metro areas.

I computed a contextually sensitive rate of affluence based on each respective metropolitan area's median household income. I defined affluent households as those households where the reported yearly income is greater than or equal to twice that of their respective metropolitan area's median household income. (The national unadjusted median household income reported in the 2000 census was $\$ 41,994$, which creates an affluent median household yearly income threshold of $\$ 83,988$. It is possible that this method overestimates the number of affluent households in low-cost areas, especially if the minimum income threshold is particularly low. The minimum median metro household yearly income in the data set was $\$ 29,104$ in 2000 . Using my method of identifying affluent households, this equates to an affluent household median household income threshold of $\$ 58,208$. The maximum median metro household yearly income was $\$ 76,554$, which equates to an affluent median household income threshold of $\$ 153,088$. Therefore, I suggest the problem of overestimating the affluence rate using my method is minimized.) Using these metropolitan area specific thresholds, I estimated the number of affluent black households, per neighborhood, from the census household income categories using Pareto interpolation [61,62].

Because of the nature of the analyses I conducted (count regression), it is necessary to account for the effect of population size with regard to determining the neighborhood concentration of affluent black households. A neighborhood's total number of households represents the theoretical upper limit of affluent households, including affluent black households, one could find in any particular neighborhood. For example, a neighborhood with fewer total households would be expected to have, all else equal, fewer affluent households than a neighborhood with a greater number of households. Therefore, I included the variable, total number of households in each neighborhood (scaled per 100 housing units), to control this population size effect.

The substantive independent variables used to test the competing theories included the following race-specific neighborhood distributions of black and white socioeconomic standing (SES): (1) The percentage of the population 25 years and older having a four-year (or more) college degree; (2) the poverty rate; (3) the per capita income (scaled per \$1000); and (4) the unemployment rate. Spatial assimilation theory suggests black and white SES should be positively associated with the dependent variable. (I was unable to differentiate between Hispanic and non-Hispanic black households or persons due to NCDB 
data constraints.) For ease of writing, I make this statement when referring to SES in abstract terms rather than when speaking to the individual variables I used to measure SES. For example, I interpreted an increase in per capita income and a decrease in the poverty rate as indicating relatively greater levels of neighborhood-level SES. Place stratification theory also suggests neighborhood-level black SES should have a positive impact on the dependent variable. However, the theory suggests neighborhood-level white SES will have a negative association with the dependent variable, thereby demonstrating high-status whites' aversion to blacks within a place-based racial hierarchy of neighborhood outcomes.

I included two variables to test for the effects of a neighborhood's racial composition: (1) The ratio between the percentage of blacks and percentage of whites, and (2) a neighborhood-level measure of group diversity (entropy index). The black-white ratio equals one when parity exists between the percentages of black and white residents, less than one when there are relatively fewer blacks, and greater than one when there are relatively more blacks than whites. I computed the group diversity index based on the proportional distribution of six mutually exclusive groups (non-Hispanic black, non-Hispanic white, non-Hispanic Asian, non-Hispanic American Indian, non-Hispanic other race, and Hispanic) in each neighborhood using the following entropy equation [63]:

$$
E_{j}=s \times \sum_{k=1}^{k}\left(\frac{k_{j}}{t_{j}} \times \ln \frac{k_{j}}{t_{j}}\right)
$$

where $k$ indexes racial groups, $j$ census tracts, and $t$ the total tract population of all racial groups. A scaling constant $s$ limits the value of the neighborhood diversity index $\left(E_{j}\right)$ from 0 (no diversity) to 1 (maximum diversity). The index achieves the minimum value when only one group is represented in a neighborhood (e.g., a neighborhood is all white); it achieves the maximum value when each of the six groups are equally represented in a neighborhood. Because spatial assimilation theory posits greater assimilation into mainstream (read whiter) neighborhoods occurs with increases in group-level human capital, one would expect a negative association with the black-white ratio. It might also suggest a positive association, up to a point, with the neighborhood diversity index as affluent black households move among neighborhoods varying from nearly all black, to an equal share of all 6 groups, to nearly all white. (By this, however, I do not mean to suggest this is a linear process of neighborhood attainment. I simply hope to convey the variety of neighborhoods affluent black households can reside within.) Interpreting the variables under the tenants of place stratification theory suggests a positive association with both the black-white ratio and neighborhood diversity index because assimilation into mainstream (i.e., predominately white) neighborhoods is limited even with black gains in human capital.

Previous literature has demonstrated neighborhood quality and demographic characteristics likely influence the neighborhood concentration of affluent households. The following variables were included as neighborhood controls: (1) Log of the median value of specified owner-occupied housing; (2) residential stability (the percentage of persons ( 5 years and older) currently living in the same house as 5 years ago); (3) percentage of residents living in group-quarters; (4) housing unit vacancy rate; and (5) percentage of renter-occupied housing units. Housing value and residential stability were expected to have a positive association while the percentage of group-quarters, vacancy rate, and percentage of renter-occupied housing units were expected to have a negative association with the neighborhood concentration of affluence because of their effect on housing value appreciation and association with lower neighborhood quality of life. (Such indicators of quality of life have been criticized for favoring middle-class norms [64].) I also included each neighborhoods' percentage of residents that are 65 years or older, 5 years or younger, and foreign-born to account for neighborhood demographic effects.

In some models, I tested for regional differences by assigning each census tract to a regional dummy variable based on its location in one of the following four census regions: Midwest, Northeast, South, and West. The South served as the excluded dummy category. In another model, I included variables for each metropolitan area's percentage of residents that are non-Hispanic black and the black-white dissimilarity index to account for metropolitan-level variation in racial 
composition and residential segregation. In a final model, I controlled for the potential effects of any excluded metropolitan-level social, demographic, or economic variables using a series of metropolitan fixed-effect dummy variables where the Atlanta metropolitan area served as the reference category.

In summary, several key neighborhood- and metropolitan-level variables facilitated testing each theory of residential attainment's ability to explain the neighborhood concentration of affluent black households. (I chose to incorporate independent variables individually, rather than as an index, to understand the unique effects of each variable as they relate to assessing whether spatial assimilation theory or place stratification theory provides for a better description of the processes associated with the neighborhood concentration of affluent black households. Please see the Methods sections, where I address potential collinearity concerns.) If spatial assimilation theory is appropriate, one should expect to find greater numbers of affluent (i.e., more) black households as the black-white ratio decreases, the level of neighborhood racial diversity increases, black and white SES increases, and metropolitan-level segregation decreases. Place stratification theory, however, suggests more affluent black households will be found as the black-white ratio increases, the level of neighborhood racial diversity increases, black SES increases, white SES decreases, and metropolitan-level segregation increases. See Table 1 for variable specific expectations on these key variables.

Table 1. Expected impact of key variables per theory of residential attainment.

\begin{tabular}{lcc}
\hline Variable & Spatial Assimilation & Place Stratification \\
\hline Black-white ratio & - & + \\
Neighborhood diversity (entropy) & + & + \\
Percent black with higher education & + & + \\
Percent non-Hispanic with higher education & + & - \\
Black poverty rate & - & + \\
Non-Hispanic white poverty rate & - & + \\
Black per capita income & + & - \\
Non-Hispanic white per capita income & + & - \\
Black unemployment rate & - & + \\
Non-Hispanic white unemployment rate & - & \\
\hline
\end{tabular}

\subsection{Methods}

Because the dependent variable is a truncated discrete count, rather than an unbounded continuous variable, standard ordinary least squares (OLS) regression is not appropriate. Such variables often have a Poisson or negative binomial distribution. An alternative to OLS, Poisson regression, restrictively assumes the conditional mean is equivalent to the conditional variance (equidispersion). Negative binomial regression analysis does not have this assumption because it accounts for the sample variance exceeding the sample mean (overdispersion) [65-68]. (The likelihood-ratio tests for all models (1 to 4) indicate one should reject the null hypothesis of the mean dispersion parameter equaling zero (H0: $\alpha=0$; Ha: $\alpha>0$ ). Significant overdisperion exists in all models; therefore, negative binomial regression is preferable to Poisson regression.) Therefore, I employ a series of cross-sectional negative binomial regression analyses to predict the number of affluent black households, per neighborhood.

Each regression analysis followed the same basic form:

$$
Y=\beta_{l} \# H H_{l}+\Sigma \beta_{\kappa} \chi_{\kappa}
$$

where $Y$ is the number of affluent black households, per neighborhood, $\beta_{l}$ is the parameter for total number of households in a neighborhood $\left(\# H H_{l}\right), \beta_{\kappa}$ is the vector of additional parameters, and $\chi_{\kappa}$ is the vector of additional variables (previously discussed) expected to influence the number of affluent black households. Because the coefficients of negative binomial regression analyses are similar to standard logistic regression, I present the coefficient results using the percentage of change in the expected count for a unit increase in the independent variable (\%-change) and the percentage of change in the expected count for a standard deviation increase in the independent variable to aid interpretation (\%StdX). The \%StdX is loosely analogous to standardized beta coefficients in standard OLS regression. 


\section{Results}

Table 2 presents (a) \%-change and (b) \%StdX in the expected number of affluent black households in a neighborhood based on four negative binomial regression equations for 2000. (Diagnostic results suggest that multicollinearity is not a problem; values for the variance inflation factors (VIF) in all models are $<5.0$, which is a commonly accepted threshold [69-72].) The \%-change coefficient indicates the percentage of increase (or decrease) in the expected number of affluent black households in a neighborhood for a one-unit increase in the independent variable. For example, in model 2, a one-unit increase in a neighborhood's percentage of blacks having higher education increases a neighborhood's predicted mean number of affluent black households by $0.5 \%$, holding all other variables constant. The \%-change for a dummy variable is interpreted as "discrete change". Using model 2 as an example again, a neighborhood located in the West has 57.3\% fewer affluent black households, on average, across neighborhoods than neighborhoods located in the South, holding all other variables constant. The \%StdX coefficient indicates the percentage of increase in the expected count for a one-standard deviation increase in the independent variable. Again, illustrating from model 2, a standard deviation increase in the percentage of blacks with college (about 17.5\%) increases a neighborhood's predicted mean number of affluent black households by approximately $9.5 \%$, holding all other variables constant.

Table 2. Percentage change in affluent black households calculated from negative binomial regressions of number of affluent black households per neighborhood, 2000.

\begin{tabular}{|c|c|c|c|c|c|c|c|c|}
\hline \multirow[t]{2}{*}{ Independent Variable } & \multicolumn{2}{|c|}{1} & \multicolumn{2}{|c|}{2} & \multicolumn{2}{|c|}{3} & \multicolumn{2}{|c|}{$4^{a}$} \\
\hline & $\%$-change & $\%$ StdX & $\%$-change & $\%$ StdX & $\%$-change & $\%$ StdX & $\%$-change & $\%$ StdX \\
\hline Black-white ratio & $14.7^{* *}$ & 123.8 & $14.5^{* *}$ & 121.1 & $12.7^{* *}$ & 101.4 & $14.5^{* *}$ & 120.9 \\
\hline $\begin{array}{l}\text { Neighborhood diversity } \\
\text { (entropy) }\end{array}$ & $4303.6^{* *}$ & 86.3 & $6167.8^{* *}$ & 97.4 & $5327.1 * *$ & 92.8 & $\underset{* *}{11,102.8}$ & 117.2 \\
\hline $\begin{array}{l}\text { Percent black with } \\
\text { higher education }\end{array}$ & $0.7^{* *}$ & 13.0 & $0.5^{* *}$ & 9.5 & $0.4^{* *}$ & 8.1 & $0.4^{* *}$ & 7.2 \\
\hline $\begin{array}{l}\text { Percent non-Hispanic white } \\
\text { with higher education }\end{array}$ & $1.0 * *$ & 20.2 & $0.7^{* *}$ & 12.9 & $0.8^{* *}$ & 15.7 & $0.8 * *$ & 16.3 \\
\hline Black poverty rate & $-1.0 * *$ & -15.9 & $-1.0 * *$ & -14.6 & $-0.9^{* *}$ & -13.9 & $-1.1^{* *}$ & -16.0 \\
\hline $\begin{array}{l}\text { Non-Hispanic white } \\
\text { poverty rate }\end{array}$ & $0.4^{* *}$ & 4.4 & $0.6^{* *}$ & 6.0 & $0.7^{* *}$ & 6.7 & $0.4^{* *}$ & 3.5 \\
\hline Black per capita income & $3.3^{* *}$ & 45.1 & $4.1^{* *}$ & 58.9 & $4.3^{* *}$ & 61.7 & $5.0 * *$ & 74.6 \\
\hline $\begin{array}{l}\text { Non-Hispanic white per } \\
\text { capita income }\end{array}$ & -1.0 & -10.4 & $-1.1^{* *}$ & -11.8 & $-1.2^{* *}$ & -12.0 & $-0.4^{* *}$ & -4.8 \\
\hline Black unemployment rate & $-0.7^{* *}$ & -6.6 & $-0.3^{* *}$ & -3.2 & $-0.5^{* *}$ & -4.4 & $-0.4^{* *}$ & -4.1 \\
\hline $\begin{array}{l}\text { Non-Hispanic white } \\
\text { unemployment rate }\end{array}$ & $0.3 *$ & 1.8 & $0.7^{* *}$ & 4.4 & $0.6^{* *}$ & 3.8 & $0.5^{* *}$ & 3.3 \\
\hline $\begin{array}{l}\text { Total number } \\
\text { of households }\end{array}$ & $4.2 * *$ & 42.6 & $3.8^{* *}$ & 38.2 & $3.9^{* *}$ & 39.9 & $3.7^{* *}$ & 36.7 \\
\hline $\begin{array}{l}\text { Percent living in } \\
\text { group quarters }\end{array}$ & $1.5^{* *}$ & 7.9 & $1.2 * *$ & 6.4 & $1.1^{* *}$ & 5.9 & $1.7^{* *}$ & 8.8 \\
\hline Percent $65+$ years old & $-1.7^{* *}$ & -10.5 & $-1.3^{* *}$ & -8.4 & $-0.9^{* *}$ & -5.6 & $-1.4^{* *}$ & -8.6 \\
\hline $\begin{array}{l}\text { Percent } 5 \text { and under } \\
\text { years old }\end{array}$ & $2.4^{* *}$ & 5.5 & $3.7^{* *}$ & 8.4 & $3.2^{* *}$ & 7.2 & $5.1 * *$ & 11.7 \\
\hline Percent foreign born & $-1.9^{* *}$ & -23.9 & $-1.8^{* *}$ & -22.8 & $-1.6^{* *}$ & -20.5 & $-1.9^{* *}$ & -23.9 \\
\hline $\begin{array}{l}\text { Log of median specified } \\
\text { owner-occupied housing }\end{array}$ & $-27.0^{* *}$ & -16.8 & -5.5 * & -3.3 & $-21.4^{* *}$ & -13.2 & $-17.9 * *$ & -10.9 \\
\hline Vacancy rate & $1.7^{* *}$ & 9.8 & $1.2 * *$ & 6.6 & $1.1^{* *}$ & 6.4 & -0.2 & -1.0 \\
\hline Percent rental units & $-0.7^{* *}$ & -14.8 & $-0.6^{* *}$ & -13.5 & $-0.8^{* *}$ & -17.3 & $-0.8^{* *}$ & -16.6 \\
\hline $\begin{array}{l}\text { Percent living in same house } \\
5 \text { years ago }\end{array}$ & $2.5^{* *}$ & 37.4 & $2.4^{* *}$ & 35.6 & $1.8^{* *}$ & 25.9 & $1.8^{* *}$ & 25.0 \\
\hline Midwest & & & $-23.3^{* *}$ & & 0.3 & & - & \\
\hline Northeast & & & $-30.4^{* *}$ & & -4.2 & & - & \\
\hline West & & & $-57.3^{* *}$ & & $-20.6^{* *}$ & & - & \\
\hline
\end{tabular}


Table 2. Cont.

\begin{tabular}{|c|c|c|c|c|c|}
\hline $\begin{array}{l}\text { Metro-level percent } \\
\text { non-Hispanic black }\end{array}$ & - & - & $-3.6^{* *}$ & 38.6 & - \\
\hline Dissimilarity index & - & - & $0.4^{* *}$ & 4.3 & - \\
\hline Number of cases & 26,686 & 26,686 & \multicolumn{2}{|c|}{26,686} & 26,686 \\
\hline Pseudo R-square & 0.049 & 0.053 & \multicolumn{2}{|c|}{0.059} & 0.074 \\
\hline Alpha & 1.356 & 1.295 & \multicolumn{2}{|c|}{1.217} & 1.057 \\
\hline
\end{tabular}

The findings across all models are fairly consistent. As anticipated, greater numbers of affluent (i.e., more) black households were found in higher-status black neighborhoods and seemed to avoid lower-status black neighborhoods. Examining the specific black SES variables reveals they all significantly affect the number of affluent black households in a neighborhood and have the expected direction of impact for both theories. The variables percentage of blacks having a four-year college degree or more and the black per capita income each have a positive effect. The black poverty rate and black unemployment rate each have a negative effect.

Perhaps not surprisingly, black per capita income has the greatest effect of all the black SES variables (as shown by the higher \%StdX coefficients). Across all models, black per capita income has a between 2.8- and 4.7-times greater impact on the expected number of affluent black households compared to the second most influential black SES variable, the percentage of blacks living in poverty. As the model expands to include the effects of region, segregation, and metro-level percentage of blacks, the influence of black per capita income increases and that of the black poverty rate decreases. Interestingly, the "rate of return" for black college education appears to weaken as the model expands, perhaps suggesting income-producing factors are less affected by neighborhood-level educational capital than factors not included in this analysis (e.g., neighborhood, regional- and/or metropolitan-level employment by occupation or industry).

By comparison, higher white neighborhood SES is not generally associated with greater numbers of affluent black households. An examination of the effect of the white SES variables shows the percentage of whites having a four-year college degree or more is the only white SES variable to have a significant and positive impact on the expected number of affluent black households found in a neighborhood. This might suggest support for spatial assimilation theory. Another interpretation of this white education effect, however, is that it is picking up the impact of specific kinds of neighborhoods located in highly segregated metropolitan areas where efforts at pro-integration policies have been enacted (e.g., Shaker Heights, Ohio) or where segments of the white community historically have been open to greater levels of integration with blacks (e.g., Jewish Americans). (See Cashin for more detail [23].) These neighborhoods of integration might represent pockets of resistance in an otherwise racially charged metropolitan environment, thereby providing greater support for place stratification theory. The remaining white SES variables provide further credence to this interpretation.

For example, the white poverty and unemployment rates are significantly and positively associated with greater numbers of affluent black households in all models. Furthermore, white per capita income has a significant and negative effect in all models. Unlike the black SES findings, however, the percentage of whites having a college education has the greatest relative impact of all the white SES variables. Across all models, the percentage of whites with a college degree has from slightly greater than parity to 3.4 times greater impact than white per capita income. Across all models, the percentage of whites with a college degree has a greater relative impact than the percentage of blacks with a college degree. These findings, taken together, suggest neighborhoods where white residents proportionately have a lower economic standing have a greater number of affluent (i.e., more) black households. Such findings are contrary to spatial assimilation theory and much more consistent with place stratification theory. 
The racial composition of a neighborhood has an important effect on the number of affluent black households found in a neighborhood. The black-white ratio and neighborhood racial diversity index variables are statistically significant and have the greatest influence across all models—even more than neighborhood-level black or white SES. The positive sign on the black-white ratio indicates the number of affluent households increases as a neighborhood's relative share of black residents, compared to that of its white residents, increases. Similarly, as a neighborhood becomes more racially and ethnically diverse (as indicated by the neighborhood group diversity index), one finds greater numbers of affluent black households, all else equal. Together, the two racial composition variables suggest affluent black households are increasingly found in comparatively blacker (non-white) neighborhoods, but not the "blackest" of neighborhoods. Furthermore, affluent black households tend to be found in racially diverse neighborhoods. These findings provide substantial support for place stratification and evidence against spatial assimilation.

I explored the effect of regional location on the expected number of affluent black households beginning with model 2. It suggests neighborhoods located in the Midwest, Northeast, and West are expected to contain fewer affluent black households, on average, compared to neighborhoods located in the South. For instance, one would expect to find approximately $23 \%, 30 \%$, and $57 \%$ fewer affluent black households, on average, in neighborhoods located in the Midwest, Northeast, and West respectively, than neighborhoods located in the South. Metropolitan-level characteristics, however, appear to affect the specific kind of the regional effect.

Once I controlled for each metropolitan area's racial composition and level of residential segregation in model 3, the South's advantage over the Midwest and Northeast dropped out. Findings suggested only the West dummy variable remains statistically significant. (Two analogous regressions where I entered each metro-level characteristic separately confirmed this finding. Including only the dissimilarity index in the model substantiates the South's statistically significant advantage over all other regions. However, when only the percentage of non-Hispanic blacks is included, the Midwest has a statistically significant advantage over the South.) Those neighborhoods located in the West now have almost $21 \%$ fewer affluent black households, on average, than neighborhoods located in the South. To explore the regional effects among neighborhoods located in the Midwest, Northeast, and West, I ran separate pairwise Wald tests (not shown); results indicated neighborhoods located in the West have significantly fewer numbers of affluent black households than those located in Midwest or Northeast, all else equal. However, the Midwest and Northeast are not significantly different from one another. The regional effect findings of models 2 and 3 are consistent with other research documenting the "return migration" of African Americans to the U.S. South. This finding may also be consistent with in-situ growth of Southern black affluence, perhaps due to the area's high concentration of historically black colleges and universities, a high concentration of black-owned businesses, or as a center for the commercialization of African American culture.

Closer examination of the metropolitan-level variables shows a significant and positive coefficient for the percentage of non-Hispanic black and black-white residential segregation. Perhaps not surprisingly, metropolitan areas where blacks represent a relatively greater share of the area's total population have greater numbers of (i.e., more) affluent blacks, all else equal, than those metropolitan areas having a smaller share. Additionally, results indicate metropolitan areas having greater levels of residential segregation have greater numbers of affluent black households at the neighborhood level. These findings suggest metropolitan-level racial composition and residential segregation may be key to understanding differences in the concentration of affluent black households at the neighborhood level in the Midwest, Northeast, and South but that additional metropolitan characteristics are needed to understand the neighborhood concentration in the West.

Some of the remaining neighborhood-level control variables have the expected effects; however, others do not. The residential stability variable displays a positive effect in all models. The percentage of renter-occupied housing units has a negative effect in all models. The median value of specified owner-occupied housing, however, indicates a negative effect in all models. The vacancy rate 
has a significant and positive effect in all models but becomes statistically insignificant once the metropolitan-level dummy variables are included in model 4 . These findings suggest greater numbers of affluent (i.e., more) black households are more likely found in relatively stable, yet lower-cost neighborhoods, all else equal. The percentage of people aged 65 years or older has a negative effect, while the percentage of people aged 5 or younger has a positive effect in all models; perhaps this reflects the comparatively lower incomes of retirees and households having small children. Additionally, the percentage of foreign-born residents has a negative effect in all models, perhaps reflecting affluent black households' aversion to living in immigrant neighborhoods.

Lastly, the percentage of residents living within group-quarters appears to have a positive effect on a neighborhood's number of affluent black households; this does not seem consistent with expectations where higher SES black households "buy into" neighborhoods with greater quality. Therefore, this may suggest support for place stratification theory in that "blacker" neighborhoods are often of "lower quality". I make these statements with caution, however, considering the great diversity in types of residences considered group-quarters (e.g., college dorms, senior assisted living homes, and prisons); it may be that many affluent black households are located in close proximity to arguably positively (or neutrally) stereotyped group-quarters (e.g., senior assisted living) rather than negatively stereotyped group-quarters (e.g., prisons).

To recap, the findings suggested greater numbers of affluent (i.e., more) black households tend to be found in neighborhoods having relatively higher black SES status and lower white SES status. A neighborhood's percentage of white residents with a college degree is the only white SES variable associated with greater numbers of affluent black households. Of all the SES variables, black per capita income has the greatest relative impact in determining the number of affluent households, while the percentage of whites with college has the second greatest impact. While increases in black per capita income are associated with greater numbers of affluent black households, increases in white per capita income are associated with fewer numbers.

Neighborhood racial composition affects the concentration of affluent black households. The black-white ratio has by far the greatest relative impact of any variable in the models, having a positive association. Additionally, there is a positive association between the number of affluent black households and neighborhood group diversity. Results from the metropolitan-level characteristics of racial composition and residential segregation complement these neighborhood-level results. Findings suggest greater numbers of affluent (i.e., more) black households are (1) found in neighborhoods located in metropolitan areas having a relatively greater share of residents identifying as black, and (2) in more residentially segregated metropolitan environments.

Those variables included in the model to control for neighborhood quality suggest greater numbers of affluent black households are found in neighborhoods having greater residential stability and lower neighborhood costs. For example, median housing value (negative) and housing vacancy (positive) had unexpected effects. Another contrary finding concerns the positive association with the percentage of persons living within group-quarters. Additionally, regional findings support the trend of "return migration", wherein blacks are increasingly living in the southern part of the country. Results found greater numbers of affluent blacks living in neighborhoods located in the South than other regions of the country, all else equal, especially compared to the West.

\section{Summary and Conclusions}

Much of the past social science research investigated a particular segment of the black community—the "underclass" — attempting to sort out the apparent "social disadvantage" of being poor and black. This focus left out the other end of the black income distribution. Less is understood about the ways in which more affluent blacks are affected by their unique racial, class, and place situation. Mainstream political liberalism and conservative economics might suggest that the significance of race declines or becomes less significant as income and wealth increases [13,73-77]. Other scholars suggest 
that race may function as a "master status", thereby limiting opportunities for all members of a racial minority group, regardless of one's particular socioeconomic status [5,12,21,22,25,36,78-80].

I began sorting through such issues of race, class, and place by examining the spatial outcomes of affluent black households at the neighborhood level during the 1990s. The main investigative thrust of this paper tested two commonly used theories of residential attainment-spatial assimilation and place stratification-to examine their utility in understanding what processes affect the neighborhood-level concentration of affluent black households. Four regression analyses were conducted to begin answering this question. Using variables derived from spatial assimilation and place stratification theory, I examined how neighborhood-level black and white SES, demographic characteristics, neighborhood quality characteristics, metropolitan-level racial composition, residential segregation, metropolitan fixed effects, and geographic region relate to the neighborhood concentration of affluent black households. Results suggested much greater support for place stratification theory and little, if any, support for spatial assimilation theory.

At the neighborhood level, SES and racial composition were key variables in deciding between each theory. At the metropolitan level, the rates of residential segregation and racial composition were important. The bulk of the evidence, however, appeared to lend greater support for place stratification operating at the neighborhood level, especially with regard to the white SES and racial composition variables. Limited evidence for spatial assimilation appeared to operate via white educational attainment at the neighborhood level. These results ran counter to other scholarship that suggests that spatial assimilation may be currently (or increasingly) more relevant to the residential geography of African Americans than in previous decades [8,32]. My research suggests that such findings may be dependent upon the unit of analysis and how one measures attainment between black and white households; the findings may suggest that forces operating at one level (e.g., individual) may not translate to other levels (e.g., neighborhood).

The findings are generally consistent in that socioeconomic variables affect the neighborhood concentration of affluent black households. The black SES variables are consistent with both spatial assimilation and place stratification theories. Increases in "positive" SES factors (e.g., income and education) are associated with greater numbers of affluent (i.e., more) black households, while increases in "negative" factors (poverty and unemployment) are associated with fewer numbers of affluent black households. The white SES variables, however, are more consistent with place stratification theory. In general, gains in neighborhood-level white SES are negatively associated with the neighborhood concentration of affluent black households. Specifically, gains in white income are negatively associated, while gains in white poverty and unemployment are positively associated with black affluence. While white educational attainment is positively associated with affluent black households, this may reflect the history of certain neighborhoods and groups of whites having a greater willingness to live among blacks in otherwise highly segregated metropolitan contexts, thereby suggesting place stratification theory better captures the racial dynamics affecting black residential outcomes than spatial assimilation theory. Consistent with previous studies, this finding suggests affluent black households may be residentially integrating with lower-status white residents.

In addition, neighborhood racial composition proves to be the single greatest set of variables predicting affluent black neighborhood outcomes and also provides greater support for place stratification theory. The neighborhood racial composition findings suggested that greater numbers of affluent black households are generally found in comparatively blacker and more diverse neighborhood settings but not the "blackest" of all neighborhoods. Considering the black-white ratio and neighborhood diversity index variables together suggests greater numbers of affluent (i.e., more) black households are found in neighborhoods having relatively fewer whites, all else equal. (While one might expect a positive association for the neighborhood diversity index under both theories, the positive association for the black-white ratio indicates greater numbers of affluent blacks are found in blacker (rather than whiter) neighborhoods, all else equal, thereby supporting place stratification theory.) Results also suggest the neighborhood concentration of affluent black households 
is positively related to neighborhood stability and negatively associated with neighborhood cost. Furthermore, neighborhoods located in more segregated metropolitan areas and having a larger share of black residents, on average, have greater numbers of affluent black households. Lastly, neighborhoods located in the southern region of the U.S. have greater numbers, on average, of affluent black households.

These findings, taken together, suggest intergroup relations between blacks and whites were likely strained and unequal during the 1990s. Furthermore, they suggest many whites may have been hesitant to live among "large numbers" of black households, including affluent black households, thereby helping to maintain and reinforce residential segregation. These findings also beg a basic question. Are greater concentrations of affluent black households at the neighborhood level a "good thing"? If so, policies designed to increase neighborhood-level black group per capita income, black educational attainment, and increase neighborhood-level diversity may be important. Furthermore, findings suggest efforts aimed at reducing residential segregation via fair housing programs and pro-integrative policies may reduce the concentration of affluent black households at the neighborhood level. Any increase in the neighborhood concentration of affluent black households, however, may come at a price if such concentrations are positively associated with affluent blacks increasingly living in lower-quality neighborhoods, on average, compared to similarly positioned affluent white households. In this case, a neighborhood dispersal strategy may be more appropriate.

This basic question reflects the complicated and potentially contentious nature of developing policies that function to increase or decrease the concentration of affluent black households. It may be that greater neighborhood concentrations of affluent black households have a threshold effect where the net social benefit increases to a particular level then begins to decrease. Perhaps paradoxically, measures to increase black SES and impose fewer barriers in the housing market may work to facilitate both a concentration and dispersal strategy by providing affluent black householders' greater ability to find housing in neighborhoods of their choice. More detailed studies are warranted to investigate the extent to which such concentrations and policies are (1) a net social benefit/cost and (2) function to reaffirm the existing neighborhood hierarchy.

Future studies should build upon the shortcomings of this research. The positive association between metro-level segregation and neighborhood concentration of affluent blacks, in particular, begs for further research investigating the ways in which residential segregation is associated with the concentration of affluent black households at the neighborhood level. Additionally, neighborhood concentrations of affluent black and white households should be compared directly to assess which theory better describes the spatial outcomes of each group. Future analysis should also focus on comparing the neighborhood outcomes of affluent white and non-Hispanic black households, which was not possible with the data sources used in this paper. Perhaps most importantly, future research should directly investigate black-white differences in neighborhood quality outcomes for affluent households to determine the extent of any existing racial inequities. Finally, and again because of the data sources used, this research did not differentiate rates of affluence for interracial households versus single-race households, a growing segment of all U.S. households [63,81,82].

Author Contributions: This article was written solely by the author; any errors are the author's responsibility.

Funding: This research received no external funding.

Acknowledgments: I want to thank Andrew Carswell, Joe Darden, Steven Holloway, and Xiaobai Angela Yao for reading early versions of this manuscript.

Conflicts of Interest: The author declares no conflict of interest. 


\section{References}

1. Massey, D.S.; Denton, N.A. Hypersegregation in U.S. Metropolitan Areas: Black and Hispanic Segregation along Five Dimensions. Demography 1989, 26, 373-391. [CrossRef] [PubMed]

2. Farley, R.; Frey, W.H. Changes in the segregation of whites from blacks during the 1980s: Small steps toward a more integrated society. Am. Sociol. Rev. 1994, 59, 23-45. [CrossRef]

3. Glaeser, E.L.; Vigdor, J.L. Racial segregation promising news. In Redefining Urban and Suburban America: Evidence from Census 2000; Katz, B., Lang, R.E., Eds.; Brookings Institution Press: Washington, DC, USA, 2003; Volume 1, pp. 211-234.

4. Logan, J.R. Ethnic Diversity Grow, Neighborhood Integration Lags. In Redefining Urban and Suburban America: Evidence from Census 2000; Katz, B., Lang, R., Eds.; Brookings Institution Pres: Washington, DC, USA, 2003; Volume 1, pp. 235-255.

5. Adelman, R.M. The roles of race, class, and residential preferences in the neighborhood racial composition of middle-class blacks and whites. Soc. Sci. Q. 2005, 86, 209-228. [CrossRef]

6. Darden, J.T.; Kamel, S.M. Black residential segregation in suburban Detroit: Empirical testing of the ecological theory. Rev. Black Polit. Econ. 2000, 27, 103-123. [CrossRef]

7. Iceland, J.; Sharpe, C.; Steinmetz, E. Class differences in African American residential patterns in US metropolitan areas: 1990-2000. Soc. Sci. Res. 2005, 34, 252-266. [CrossRef]

8. Iceland, J.; Wilkes, R. Does Socioeconomic Status Matter? Race, Class, and Residential Segregation. Soc. Probl. 2006, 53, 248-273. [CrossRef]

9. Malega, R.; Stallings, R.Y. Regional Differences in Affluent Black and Affluent White Residential Outcomes. Geogr. Rev. 2016, 106, 72-91. [CrossRef]

10. Massey, D.S.; Fischer, M.J. Does Rising Income Bring Integration? New Results for Blacks, Hispanics, and Asians in 1990. Soc. Sci. Res. 1999, 28, 316-326. [CrossRef]

11. Jargowsky, P.A. Poverty and Place: Ghettos, Barrios, and the American City; Russell Sage Foundation: New York, NY, USA, 1997; ISBN 0871544059.

12. Massey, D.S.; Denton, N.A. American Apartheid: Segregation and the Making of the Underclass; Harvard University Press: Cambridge, MA, USA, 1993; ISBN 0674018214.

13. Wilson, W.J. The Truly Disadvantaged: The Inner City, the Underclass, and Public Policy; University of Chicago Press: Chicago, IL, USA, 1987; ISBN 0226901300.

14. Clark, W.A.V. Race, class, and place: Evaluating mobility outcomes for African Americans. Urban Aff. Rev. 2007, 41, 295-314. [CrossRef]

15. Clark, W.A.V.; Blue, S.A. Race, class, and segregation patterns in US immigrant gateway cities. Urban Aff. Rev. 2004, 39, 667-688. [CrossRef]

16. Clark, W.A.V. Ethnic preferences and ethnic perceptions in multi-ethnic settings. Urban Geogr. 2002, 23, 237-256. [CrossRef]

17. Clark, W.A.V. Changing Residential Preferences across Income, Education, and Age Findings from the Multi-City Study of Urban Inequality. Urban Aff. Rev. 2009, 44, 334-355. [CrossRef]

18. Clark, W.A.V. Residential Preferences and Neighborhood Racial Segregation-A Test of the Schelling Segregation Model. Demography 1991, 28, 1-19. [CrossRef] [PubMed]

19. Alba, R.D.; Logan, J.R.; Stults, B.J. How Segregated Are Middle-Class African Americans? Soc. Probl. 2000, 47, 543-558. [CrossRef]

20. Quillian, L. Why Is Black-White Residential Segregation So Persistent?: Evidence on Three Theories from Migration Data. Soc. Sci. Res. 2002, 31, 197-229. [CrossRef]

21. Yinger, J. Closed Doors, Opportunities Lost: The Continuing Cost of Housing Discrimination; Russell Sage Foundation: New York, NY, USA, 1995.

22. Adelman, R.M. Neighborhood opportunities, race, and class: The black middle class and residential segregation. City Community 2004, 3, 43-63. [CrossRef]

23. Cashin, S. (The Failures of) Integration: How Race and Class Are Undermining the American Dream, 1st ed.; Public Affairs: New York, NY, USA, 2004; ISBN 158648124X.

24. Lacy, K.R. Black spaces, black places: Strategic assimilation and identity construction in middle-class suburbia. Ethn. Racial Stud. 2004, 27, 908-930. [CrossRef] 
25. Pattillo-McCoy, M. Black Picket Fences: Privilege and Peril among the Black Middle Class; University of Chicago Press: Chicago, IL, USA, 1999; ISBN 0226649288.

26. Pattillo, M. Black Middle-Class Neighborhoods. Annu. Rev. Sociol. 2005, 31, 305-329. [CrossRef]

27. Massey, D.S. Ethnic and residential segregation: A theoretical and empirical review. Sociol. Soc. Res. 1985, 69, 315-350.

28. Massey, D.S.; Denton, N.A. Spatial Assimilation as a Socioeconomic Outcome. Am. Sociol. Rev. 1985, 50, 94-106. [CrossRef]

29. Freeman, L. Does spatial assimilation work for black immigrants in the US? Urban Stud. 2002, 39, $1983-2003$. [CrossRef]

30. Clark, W.A.V.; Ware, J. Trends in residential integration by socioeconomic status in Southern California. Urban Aff. Rev. 1997, 32, 825-843. [CrossRef]

31. Iceland, J. Beyond Black and White: Metropolitan residential segregation in multi-ethnic America. Soc. Sci. Res. 2004, 33, 248-271. [CrossRef]

32. Freeman, L. Is Class Becoming a More Important Determinant of Neighborhood Attainment for African-Americans? Urban Aff. Rev. 2008, 44, 3-26. [CrossRef]

33. Alba, R.D.; Nee, V. Rethinking Assimilation Theory for a New Era of Immigration. In The Handbook of International Migration: The American Experience; Hirschman, C., Kasinitz, P., DeWind, J., Eds.; Russell Sage Foundation: New York, NY, USA, 1999; Volume 31, pp. 137-160.

34. Allen, J.P.; Turner, E. Spatial patterns of immigrant assimilation. Prof. Geogr. 1996, 48, 140-155. [CrossRef]

35. Darden, J.T. Afro-Americans in Pittsburgh: The Residential Segregation of a People; D.C. Heath and Company: Lexington, Kentucky, 1973.

36. Darden, J.T.; Kamel, S.M. Black Residential Segregation in the City and Suburbs of Detroit: Does Socioeconomic Status Matter? J. Urban Aff. 2000, 22, 1-13. [CrossRef]

37. Farley, R. Race still matters: The minimal role of income and housing cost as causes of housing segregation in St. Louis, 1990. Urban Aff. Rev. 1995, 31, 244-254. [CrossRef]

38. Kantrowitz, N. Ethnic and Racial Segregation on the New York Metropolis: Residential Patterns among White Ethnic Groups, Blacks, and Puerto Ricans; Praeger: New York, NY, USA, 1973.

39. Oliver, M.L.; Shapiro, T.M. Black Wealth/White Wealth: A New Perspective on Racial Inequality; Routledge: New York, NY, USA, 1995; ISBN 0415913756.

40. Alba, R.D.; Logan, J.R. Minority proximity to whites in suburbs: An individual-level analysis of segregation. Am. J. Sociol. 1993, 98, 1388-1427. [CrossRef]

41. Charles, C.Z. The Dynamics of Racial Residential Segregation. Annu. Rev. Sociol. 2003, 29, $167-207$. [CrossRef]

42. Logan, J.R.; Alba, R.D. Locational returns to human capital: Minority access to suburban community resources. Demography 1993, 30, 243-268. [CrossRef]

43. Ross, S.L.; Turner, M.A. Housing Discrimination in Metropolitan America: Explaining Changes between 1989 and 2000. Soc. Probl. 2005, 52, 152-180. [CrossRef]

44. Turner, M.A.; Galster, G.; Yinger, J. Discrimination in Metropolitan Housing Markets: National Results from Phase I HDS 2000; The Urban Institute, Metropolitan Housing and Communities Policy Center: Washington, DC, USA, 2002.

45. Charles, C.Z. Can We Live Together? Racial Preferences and Neighborhood Outcomes. In The Geography of Opportunity: Race and Housing Choice in Metropolitan America; de Briggs, X.S., Ed.; Brookings Institution Press: Washington, DC, USA, 2005; pp. 45-80.

46. Krysan, M. Whites who say they'd flee: Who are they, and why would they leave? Demography 2002, 39, 675-696. [CrossRef] [PubMed]

47. Bobo, L.; Zubrinsky, C.L. Attitudes on residential integration: Perceived status differences, mere in-group preference, or racial prejudice? Soc. Forces 1996, 74, 883-909. [CrossRef]

48. Farley, R.; Fielding, E.L.; Krysan, M. The residential preferences of blacks and whites: A four-metropolis analysis. Hous. Policy Debate 1997, 8, 763-800. [CrossRef]

49. Freeman, L. Minority Housing Segregation: A Test of Three Perspectives. J. Urban Aff. 2000, $22,15-35$. [CrossRef]

50. Zubrinsky, C.L.; Bobo, L. Prismatic Metropolis: Race and residential segregation in the city of the angels. Soc. Sci. Res. 1996, 25, 335-374. [CrossRef] [PubMed] 
51. Krysan, M. Community undesirability in black and white: Examining racial residential preferences through community perceptions. Soc. Probl. 2002, 49, 521-543. [CrossRef]

52. Chambers, D.N. The racial housing price differential and racially transitional neighborhoods. J. Urban Econ. 1992, 32, 214-232. [CrossRef]

53. Cutler, D.M.; Glaeser, E.L.; Vigdor, J.L. The Rise and Decline of the American Ghetto. J. Polit. Econ. 1999, 107, 455-506. [CrossRef]

54. Kiel, K.A.; Zabel, J.E. House Price Differentials in U.S. Cities: Household and Neighborhood Racial Effects. J. Hous. Econ. 1996, 5, 143-165. [CrossRef]

55. Krysan, M.; Farley, R. The Residential Preferences of Blacks: Do They Explain Persistent Segregation? Soc. Forces 2002, 80, 937-980. [CrossRef]

56. Geolytics, Inc. Neighborhood Change Database 1970-2010 (DVD); Geolytics, Inc.: Branchburg, NJ, USA, 2003.

57. St. John, C. The Concentration of Affluence in the United States, 1990. Urban Aff. Rev. 2002, 37, 500-520. [CrossRef]

58. Smith, J.P. Poverty and the Family. In Divided Opportunities: Minorities, Poverty, and Social Policy; Sandefur, G.D., Tienda, M., Eds.; Plenum: New York, NY, USA, 1988; pp. 141-172.

59. Coulton, C.J.; Chow, J.; Wang, E.C.; Su, M. Geographic Concentration of Affluence and Poverty in 100 Metropolitan Areas, 1990. Urban Aff. Rev. 1996, 32, 186-216. [CrossRef]

60. Massey, D.S.; Eggers, M.L. The Spatial Concentration of Affluence and Poverty during the 1970s. Urban Aff. Rev. 1993, 29, 299-315. [CrossRef]

61. Berube, A.; Tiffany, T.; Thacher, T.; Tiffany, T. The Shape of the Curve: Household Income Distributions in U.S. Cities, 1979-1999; Brookings Institution: Washington, DC, USA, 2004.

62. Booza, J.C.; Cutsinger, J.M.; Galster, G.C. Where Did They Go? The Decline of Middle-Income Neighborhoods in Metropolitan America; Brookings Institution: Washington, DC, USA, 2006.

63. Holloway, S.R.; Ellis, M.; Wright, R.; Hudson, M. Partnering "out" and fitting in: Residential segregation and the neighbourhood contexts of mixed-race households. Popul. Space Place 2005, 11, 299-324. [CrossRef]

64. Bauder, H. Neighbourhood Effects and Cultural Exclusion. Urban Stud. 2002, 39, 85-93. [CrossRef]

65. Agresti, A. An Introduction to Categorical Data Analysis, 2nd ed.; Wiley-Interscience: Hoboken, NJ, USA, 2007; ISBN 9780471226185.

66. Beck, E.M.; Tolnay, S.E. Analyzing Historical Count Data-Poisson and Negative Binomial Regression-Models. Hist. Methods 1995, 28, 125-131. [CrossRef]

67. Bishop, P.; Gripaios, P.; Bristow, G. Determinants of call centre location: Some evidence for UK urban areas. Urban Stud. 2003, 40, 2751-2768. [CrossRef]

68. Long, J.S.; Freese, J. Regression Models for Categorical Dependent Variables Using Stata; Stata Press: College Station, TX, USA, 2001; ISBN 1881228622.

69. Hair, J.F.; Anderson, R.E.; Tatham, R.L.; Black, W. Multivariate Data Analysis, 3rd ed.; Macmillan: New York, NY, USA, 1995; ISBN 0023489804.

70. Menard, S.W.C.N. Applied Logistic Regression Analysis; Sage Publications: Thousand Oaks, CA, USA, 1995; ISBN 0803957572.

71. Montgomery, D.C.; Peck, E.A. Introduction to Linear Regression Analysis; Wiley: New York, NY, USA, 1982; ISBN 0471058505.

72. O’Brien, R.M. A Caution Regarding Rules of Thumb for Variance Inflation Factors. Qual. Quant. 2007, 41, 673-693. [CrossRef]

73. Sowell, T. Civil Rights: Rhetoric or Reality? 1st ed.; W. Morrow: New York, NY, USA, 1984; ISBN 0688031137.

74. Sowell, T. Inside American Education: The Decline, the Deception, the Dogmas; Free Press: New York, NY, USA, 1992; ISBN 0029303303.

75. Sowell, T. Race and Culture: A World View; Basic Books: New York, NY, USA, 1994; ISBN 0465067964.

76. Williams, W.E. The State against Blacks; New Press: New York, NY, USA, 1982; ISBN 0070703787.

77. Wilson, W.J. The Declining Significance of Race; University of Chicago Press: Chicago, IL, USA, 1978.

78. Bonilla-Silva, E. White Supremacy and Racism in the Post-Civil Rights Era; Lynne Rienner Publishers: Boulder, CO, USA, 2001; ISBN 1588260046.

79. Bonilla-Silva, E. From bi-racial to tri-racial: Towards a new system of racial stratification in the USA. Ethn. Racial Stud. 2004, 27, 931-950. [CrossRef] 
80. Pattillo-McCoy, M. The Limits of Out-Migration for the Black Middle Class. J. Urban Aff. 2000, 22, $225-241$. [CrossRef]

81. Ellis, M.; Wright, R.; Parks, V. The immigrant household and spatial assimilation: Partnership, nativity, and neighborhood location. Urban Geogr. 2006, 27, 1-19. [CrossRef]

82. Wright, R.; Ellis, M.; Parks, V. Re-placing whiteness in spatial assimilation research. City Community 2003, 4, 111-135. [CrossRef] 